\title{
The role of microtubule actin cross-linking factor 1 (MACF1) in the Wnt signaling pathway
}

\author{
Hui-Jye Chen, ${ }^{1}$ Chung-Ming Lin, ${ }^{1}$ Chyuan-Sheng Lin, ${ }^{2}$ Raul Perez-Olle, ${ }^{1}$ Conrad L. Leung, ${ }^{1}$ \\ and Ronald K.H. Liem ${ }^{1,3}$ \\ ${ }^{1}$ Department of Pathology and Cell Biology, College of Physicians and Surgeons, Columbia University, New York, \\ New York 10032, USA; ${ }^{2}$ Department of Ophthalmology, College of Physicians and Surgeons, Columbia University, \\ New York, New York 10032, USA
}

\begin{abstract}
MACF1 (microtubule actin cross-linking factor 1) is a multidomain protein that can associate with microfilaments and microtubules. We found that MACF1 was highly expressed in neuronal tissues and the foregut of embryonic day 8.5 (E8.5) embryos and the head fold and primitive streak of E7.5 embryos. $M A C F 1^{-/-}$mice died at the gastrulation stage and displayed developmental retardation at E7.5 with defects in the formation of the primitive streak, node, and mesoderm. This phenotype was similar to Wnt-3 ${ }^{-/-}$and LRP5/6 double-knockout embryos. In the absence of Wnt, MACF1 associated with a complex that contained Axin, $\beta$-catenin, GSK3 $\beta$, and APC. Upon Wnt stimulation, MACF1 appeared to be involved in the translocation and subsequent binding of the Axin complex to LRP6 at the cell membrane. Reduction of MACF1 with small interfering RNA decreased the amount of $\beta$-catenin in the nucleus, and led to an inhibition of Wnt-induced TCF/ $\beta$-catenin-dependent transcriptional activation. Similar results were obtained with a dominant-negative MACF1 construct that contained the Axin-binding region. Reduction of MACF1 in Wnt-1-expressing P19 cells resulted in decreased $T$ (Brachyury) gene expression, a DNA-binding transcription factor that is a direct target of $\mathrm{Wnt} / \boldsymbol{\beta}$-catenin signaling and required for mesoderm formation. These results suggest a new role of MACF1 in the Wnt signaling pathway.
\end{abstract}

[Keywords: MACF1-knockout mice; Wnt signaling; Axin translocation; LRP5/6; embryonic lethality; primitive streak; mesoderm]

Supplemental material is available at http://www.genesdev.org.

Received January 19, 2006; revised version accepted May 16, 2006.

Plakins (spectraplakins) are linker proteins that connect the cytoskeletal network to membrane-associated junctional complexes and are important in maintaining tissue integrity. MACF1 (microtubule actin cross-linking factor 1), also called ACF7 (actin cross-linking factor 7), and BPAG1 (bullous pemphigoid antigen 1) belong to the plakin family along with desmoplakin, plectin, envoplakin, periplakin, and epiplakin (Leung et al. 2002). The transcripts of MACF1 and BPAG1 are alternatively spliced resulting in different isoforms with different functional domains. MACF1a and BPAGla have similar domain organization with an actin-binding domain, a plakin domain that can bind junctional complexes, a rod domain with spectrin repeats, and a $\mathrm{C}$ terminus that can bind and stabilize microtubules (Leung et al. 1999;

${ }^{3}$ Corresponding author.

E-MAIL RKL2@columbia.edu; FAX (212) 305-5498.

Article published online ahead of print. Article and publication date are online at http://www.genesdev.org/cgi/doi/10.1101/gad.1411206.
Karakesisoglou et al. 2000; Sun et al. 2001). The alternatively spliced isoforms, MACF1b and BPAG1b, contain variable numbers of plakin (or plectin) repeats between the plakin domain and spectrin repeats. MACF1b is involved in maintaining the structure of the Golgi complex (Lin et al. 2005). In epithelial cells, another alternatively spliced isoform of BPAG1 (BPAG1e) forms a link between hemidesmosomes and keratin intermediate

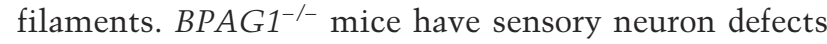
due to the absence of BPAG1a in the nervous system. Even though BPAG1 is ubiquitously expressed, degeneration is only observed in sensory neurons, suggesting that MACF1 might compensate for BPAG1 in other regions.

MACF1 homologs have been identified in Drosophila (shortstop or shot) and Caenorhabditis elegans (Vab-10). Mutations of shot result in defects in epidermal integrity, epidermal muscle attachment, muscle-dependent tendon cell differentiation, anastomosis of the tracheal branches, axonal outgrowth and guidance, and dendritic morphogenesis (for review, see Roper and Brown 2003). 
In C. elegans, Vab-10 mutants display elongation and body morphology defects (Bosher et al. 2003).

MACF1 is expressed ubiquitously in mouse embryos, with the highest levels in the nervous system followed by skeletal muscles and myocardia (Leung et al. 1999). In keratinocytes, MACF1 colocalizes with microtubules and actin at the cell periphery and relocates to sites of cell-cell contact upon stimulation (Karakesisoglou et al. 2000). MACF1-null endodermal cells fail to sustain polarization signals and to coordinate cell migration in response to wounding (Kodama et al. 2003).

The Wnt family of secreted glycoproteins is a family of signaling molecules that regulate development at different stages, from patterning of the embryo, generation of tissues, and specification of cell fate, to regulation of cell movement, polarity, axon guidance, and synapse formation (Packard et al. 2003; Strutt 2003; Veeman et al. 2003; Nusse 2005). In the absence of Wnt, a complex of $\beta$-catenin, Axin, GSK3 $\beta$, and APC (adenomatous polyposis coli) is present in the cytoplasm. GSK $3 \beta$ phosphorylates $\beta$-catenin, thereby targeting it for degradation. When Wnt binds to its receptor Frizzled and coreceptor LRP5/6, Axin is recruited to the cell membrane where it binds LRP5 and is subsequently subjected to degradation. As a result, GSK3 $\beta$ no longer phosphorylates $\beta$-catenin, and $\beta$-catenin goes to the nucleus, where it complexes with TCF/LEF proteins to activate the transcription of Wnt target genes.
We have generated $M A C F 1^{-/-}$mice and found that they died prenatally. $M A C F 1^{-/-}$embryos lacked a primitive streak, node, and mesoderm. This $M A C F 1^{-/-}$phenotype was similar to the phenotypes of $W n t-3^{-/-}$and LRP5/6 double-knockout mice. MACF1 interacted directly with Axin and was involved in the translocation of the Axin complex from the cytoplasm to the plasma membrane. The absence of MACF1 blocked Axin translocation and inhibited the downstream $\beta$-catenin/TCF transcriptional activation, indicating that MACF1 acted as a positive regulator in the Wnt signaling pathway.

\section{Results}

\section{Generation of $\mathrm{MACF}^{-/-}$mice}

We isolated a mouse MACF1 genomic clone from a SV129 genomic library and used it to construct the MACF1 targeting vector (Fig. 1A). Exons 26 and 27 and portions of exons 25 and 28 were targeted for deletion and replaced by a neomycin-resistance cassette. These targeted exons encoded amino acids 1053-1230, common to all MACF1 isoforms. Two $\mathrm{MACF1}^{+/-}$embryonic stem (ES) cell clones were isolated to create two independent transgenic mouse lines that were maintained under a C57BL/6J background. Genomic PCR and Southern blots were used to genotype the transgenic animals. When genomic DNA was digested with $\mathrm{XbaI}$, the mutant
Figure 1. Targeted disruption of the mouse MACF1 gene. (A) Genomic organization and partial restriction maps of the mouse MACF1 locus, targeting vector, and targeted locus. The domains are marked above the construct. ( $\mathrm{Xb}$ and $\mathrm{Xh}) \mathrm{XbaI}$ and Xhol restriction sites; (neo) a cassette for neomycin phosphotransferase; (arrows) genotyping PCR primers; the position of the Southern blot probe is shown. $(B)$ Southern blot analysis of E10.5 mice. The wild-type and mutant alleles generated 10.5-kb and 3.4-kb XbaI fragments, respectively. (C) PCR genotyping of E10.5 embryos. Products from wild-type animals and mutants are $3.0 \mathrm{~kb}$ and $1.8 \mathrm{~kb}$, respectively. $(+/+)$ Wild-type mouse; (+/-) heterozygous mouse; (-/-) homozygous-null mouse. (D) Genotypes of progeny from heterozygous matings. The pooled data from several litters are shown. (NA) Not available. $(E-G)$ Whole-mount immunohistochemistry with anti-MACF1 antibody. (E) In the wild-type E7.5 embryo, MACF1 was expressed in the neural fold and primitive streak. $(F)$ No MACF1 staining was observed in MACF1null embryos. $(G)$ In the wild-type E8.5 embryo, MACF1 protein was widely expressed, except in the allantois (arrow). (H) RT-PCR analyse of MACF1 and BPAG1 at E7, E11, $\mathrm{E} 15$, and E17. (BPAG1) All BPAG1 isoforms; (BPAG1a/b) BPAG1a and BPAG1b isoforms; (GAPDH) glyceraldehyde-3-phosphate dehydrogenase, loading control.

A

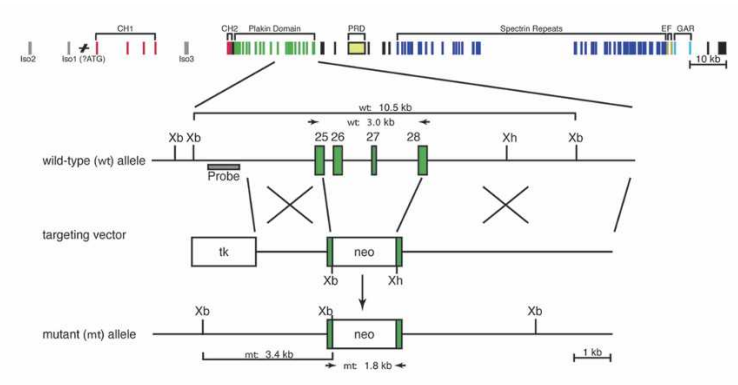

B

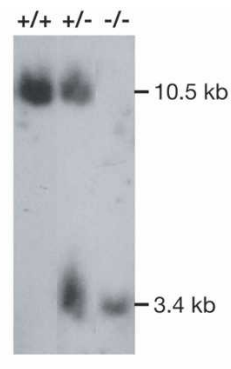

C

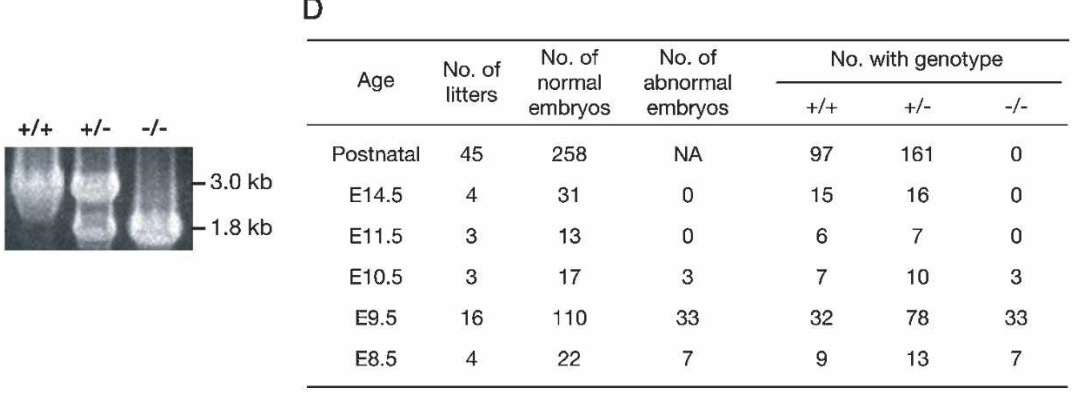

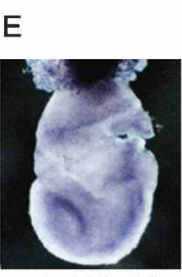

E7.5 (+/+)
F

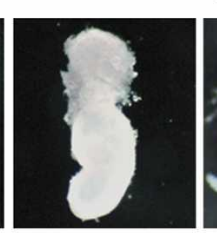

E7.5 (-l-)
G

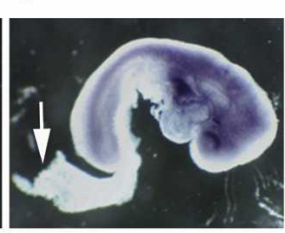

E8.5 $(+/+)$
$\mathrm{H}$

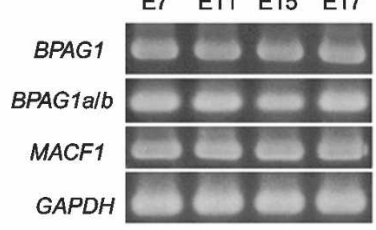


and wild-type alleles generated 3.4- and 10.5-kb bands, respectively (Fig. 1B). Genomic PCR amplified 1.8- and 3.0-kb fragments for the mutant and wild-type alleles (Fig. 1C). Heterozygous $\mathrm{MACF1}^{+/-}$mice were fertile with no overt phenotype. Mating of $\mathrm{MACF}^{+/-}$mice produced only wild-type and heterozygous offspring with an $\sim 1: 2$ ratio, suggesting that $\mathrm{MACF1}^{-/-}$embryos died before birth. Genotyping of embryos from early developmental stages indicated that $\mathrm{MACF}^{-/-}$embryos did not survive beyond embryonic day 11.5 (E11.5) (Fig. 1D). Mutant embryos collected before E11.5 were generally smaller in size, but implantation did not appear to be affected.

We performed whole-mount immunohistochemistry with anti-MACF1 CU119 antibody (Lin et al. 2005) on wild-type and mutant embryos. MACF1 was ubiquitously expressed at E7.5, with the highest levels in the head fold and in the primitive streak of the wild-type embryo (Fig. 1E). No signal was detected in mutant embryos (Fig. 1F). At E8.5, MACF1 protein was ubiquitously expressed with the exception of the allantois. The strongest MACF1 staining was in neural tissues (especially forebrain) and in the foregut (Fig. 1G). These data demonstrated that MACF1 protein was expressed at the gastrulation stage and that there was no MACF1 protein present in $\mathrm{MACF1}^{-/-}$embryos.

\section{MACF1 and BPAG1 may play different biological roles in vivo}

MACF1 and BPAG1 are closely related members of the plakin family and therefore might have overlapping functions. BPAG1 $1^{-/-}$mice survive until weaning and suffer primarily from sensory neuron degeneration, while $\mathrm{MACF1}^{-1-}$ mice die prenatally. Therefore, either BPAG1 did not compensate for MACF1 in the MACF1 $1^{-/-}$ embryos, or BPAG1 was not yet expressed at E7.5. We analyzed the expression patterns of BPAG1 isoforms and MACF1 at different developmental stages. As shown in Figure $1 \mathrm{H}, \mathrm{mRNAs}$ of MACF1 and all BPAG1 isoforms were readily detected from E7 to E17 mouse embryonic stages, suggesting that BPAG1 could not compensate for the absence of MACF1 in the knockout embryo. Therefore, BPAG1 and MACF1 are not completely functionally redundant and may play different biological roles in vivo.

Lack of primitive streak, node, and mesoderm in $\mathrm{MACF}^{-1-}$ embryos

$M A C F 1^{-1-}$ mice died early during development. To determine whether MACF1-null embryos exhibited any defects in cell death or cell proliferation, we performed TUNEL assays and immunostaining with anti-phosphoHistone H3 on E8.5 embryos. TUNEL assays showed very little or no apoptotic cell death in either wild-type or $\mathrm{MACF1}^{-/-}$embryos, while anti-phospho-histone H3 stainings revealed that cells of the mutant embryos were still undergoing active proliferation at E8.5 (data not shown). We performed histological analyses on E9.5 and
E7.5 embryos. At E9.5, MACF1 ${ }^{-/-}$embryos appeared to have stopped developing at an earlier embryonic stage (around E7.5) when compared with wild-type littermates. The $M A C F 1^{-/-}$embryos had a neural plate (Fig. 2, cf. $\mathrm{A}$ and $\mathrm{B})$, but there was no evidence of primitive streak and mesoderm formation (Fig. 2B). The primitive streak and the mesodermal layer were also absent in earlier E7.5 $\mathrm{MACF}^{-1-}$ embryos, indicating that these structures did not form in the absence of MACF1 (Fig. 2C,D). The $M A C F 1^{-1-}$ embryos appeared to die at the gastrulation period, during the formation of the endoderm, mesoderm, and ectoderm.

We analyzed the expression patterns of various tissuespecific markers in E7.5 embryos. T (Brachyury) encodes a DNA-binding transcription factor that can be used to
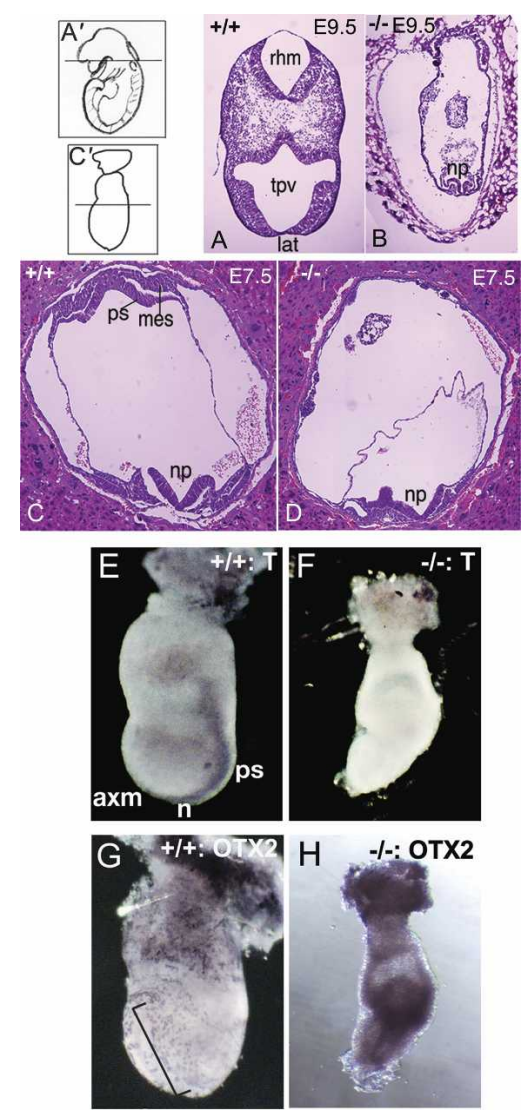

Figure 2. Histological and tissue-specific marker analyses of $M A C F 1^{-/-}$embryos. $(A-D) \mathrm{H} \& \mathrm{E}$ staining of transverse cryosections of E9.5 wild-type $(A)$ and mutant $(B)$ embryos, and E7.5 wild-type $(C)$ and mutant $(D)$ embryos. (np) Neural plate; (rhm) rhombomere; (tpv) telencephalic vesicle; (lat) lamina terminalis; (ps) primitive streak; and (mes) mesoderm. $A^{\prime}$ and $C^{\prime}$ show the location of the sectioning site of E9.5 and E7.5 embryos, respectively. $(E-H)$ Whole-mount in situ immunohistochemistry analyses of E7.5 wild-type $(E, G)$ and MACF1 mutant $(F, H)$ embryos. The embryos are shown with the anterior facing the left. T was expressed in the primitive streak (ps), node (n), and axial mesoderm $(\mathrm{axm})$ of the control embryo $(E)$; these structures were absent in the mutant embryo and resulted in no $\mathrm{T}$ staining $(F)$. OTX2 is expressed in the anterior neuroectoderm of control embryo (bracket; $G$ ) and mutant embryo $(H)$. 
detect the primitive streak, node, and axial mesoderm (Willison 1990). T staining was observed in wild-type embryos, but not in $M A C F 1^{-/-}$embryos (Fig. 2E,F). These results indicated that the primitive streak, node, and axial mesoderm failed to develop in E7.5 $\mathrm{MACF}^{-/-}$ embryos. To determine if the ectoderm of MACF1 mutant embryos had acquired a regional pattern, we examined Otx2 expression. Otx2 is expressed ubiquitously in all germinal layers in the early streak-stage embryo and is down-regulated in the posterior region of the embryo, but maintained in the anterior region at the mid-streak stage (Simeone et al. 1993). We detected Otx2 at the anterior neuroectoderm, in the region that encompassed the prospective forebrain and midbrain in wild-type E7.5 embryos (Fig. 2G), whereas it was present throughout the entire ectoderm in $M A C F 1^{-/-}$embryos (Fig. $2 \mathrm{H}$ ). To examine whether the ectoderm of mutant embryos was differentiated, we used the epiblast marker Pou5f1. Pou5f1 is expressed in the epiblast before gastrulation and is down-regulated as epiblasts start differentiation (Rosner et al. 1990). In $M A C F 1^{-/-}$mutants, no signal was detected in the entire ectoderm, indicating that the ectodermal cells were fully differentiated from the epiblasts (Supplementary Fig. S1). These data suggested that $M A C F 1^{-1-}$ mutants passed the E6.5 stage and acquired an anterior neuroectoderm. We also examined the formation of prospective forebrain and anterior visceral endoderm (AVE) with Hesxl and Lhx1 markers and found no obvious differences between wild-type and mutant embryos (Supplementary Fig. S1). Thus, the histological and molecular marker analyses suggested that $M A C F 1^{-/-}$ embryos were able to form the neural plate, but not the primitive streak, the node, and the mesoderm.

MACF1 associates with a complex containing APC, Axin, $\beta$-catenin, and GSK3 $\beta$

The defects of $M A C F 1^{-/-}$embryos in the formation of primitive streak, node, and mesoderm were similar to

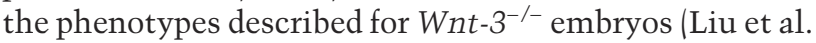
1999 ) and LRP5/6 double-knockout embryos (Kelly et al. 2004). In addition, $M A C F 1^{-/-}$embryos showed no staining for $\mathrm{T}$ (Brachyury), a target gene of the Wnt/ $\beta$-catenin signaling pathway (Arnold et al. 2000), suggesting that MACF1 could be a component of the Wnt/ $\beta$-catenin pathway. To test this hypothesis, we first studied whether MACF1 could interact with proteins in the Axin complex by coimmunoprecipitation assays. We found that anti-MACF1 antibody coimmunoprecipitated APC, $\beta$-catenin, GSK3 $\beta$, and Axin in PC12 cells (Fig. 3A). Similar results were also obtained in Rat-1/LacZ cells (Fig. 3B; Young et al. 1998). Due to the low cellular concentration of Axin (Lee et al. 2003) and high background staining of the antibody, the coimmunoprecipitated Axin was difficult to detect. We therefore confirmed the interaction between MACF1 and Axin by coimmunoprecipitation assays using lysates from cells that were transfected with a c-Myc-tagged Axin construct (Fig. 3C). MACF1 is also known to interact with actin filaments and microtubules; however, no actin or tubulin coimmunoprecipitated with MACF1 in these experiments (data not shown), probably because MACF1 only binds to polymerized actin and microtubules. Coimmunoprecipitation assays with anti-APC also indicated that APC associated with MACF1, $\beta$-catenin, Axin, and GSK3 $\beta$ (Fig. $3 \mathrm{D})$. Together, these results suggested that MACF1 was a component of the APC/Axin complex. A protein complex of $>10^{3} \mathrm{kDa}$ that contains APC, Axin, GSK3 $\beta$, and $\beta$-catenin has been isolated by gel filtration in mammalian cells (Kishida et al. 1999; Kikuchi 2000). Since the molecular masses of APC, Axin, GSK3 $\beta$, and $\beta$-catenin total $\sim 550 \mathrm{kDa}$, the $600-\mathrm{kDa}$ MACF1 could be part of this large complex.

\section{MACF1 knockdown inhibited the Wnt signaling pathway}

Wnt-1, Wnt-3, and Wnt-3a all induce TCF/LEF transcriptional activation through $\beta$-catenin (Young et al. 1998). To determine whether MACF1 is involved in Wnt $/ \beta$ catenin signaling, we used P19 cells, a mouse pluripotent embryonic carcinoma cell line, as well as two Rat-1 stable fibroblast lines; one expressing Wnt-1 (Rat-1/Wnt$1)$ and the other $\beta$-galactosidase (Rat-1/LacZ, negative control). We knocked down MACF1 using small interfering RNA (siRNA). The efficiency of the MACF1 siRNA vector in knocking down MACF1 was examined by Western blotting. As shown in Figure 3E, the MACF1 siRNA vector significantly reduced the level of MACF1 by $\sim 65 \%$ in two different cell lines. We then transfected the siRNA vector together with an optimized TCF/LEF luciferase reporter construct, pGL3-OT, and Renilla luciferase plasmids into the $\mathrm{P} 19$ cells and the Rat-1/Wnt-1 and Rat-1/LacZ cells and monitored the luciferase activities. P19 cells treated with Wnt-3a-conditioned medium had $\sim 30$-fold higher TCF/ $\beta$-catenin-mediated luciferase activity than $\mathrm{P} 19$ cells treated with control medium. Reduction of MACF1 protein by siRNA decreased the luciferase activity in $\mathrm{P} 19$ cells by $85 \%$ upon Wnt-3a induction (Fig. 3F). The luciferase activities were similar in P19 cells that were transfected with the MACF1 siRNA or control siRNA vector but treated with control medium (Fig. 3F). When a control mutant TCF-Luciferase reporter (pGL3-OF) was used, no activation was detected (data not shown). We also studied the effect of knocking down MACF1 in the TGF $\beta$ signaling pathway. The activation of a TGF $\beta$-Luciferase reporter (pSBE4-luc) by TGF $\beta$ was not changed in MACF1-knockdown cells (Fig. $3 F)$, demonstrating that MACF1 siRNA-mediated inhibition was specific to the Wnt signaling pathway.

In addition to P19 cells, we used another in vivo system, viz. the Rat-1/Wnt-1 and Rat-1/lacZ cells to study MACF1 and Wnt signaling (Young et al. 1998). The Wnt1-expressing Rat-1/Wnt-1 cells had 23-fold as much luciferase activity as the control Rat-1/lacZ cells. The latter was unchanged after transfection of MACF1 siRNA vector. However, Rat-1/Wnt-1 cells transfected with the MACF1 siRNA vector only had $17 \%$ of the luciferase activity of the cells treated with the control siRNA (Fig. 
A

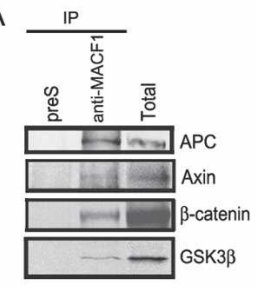

B

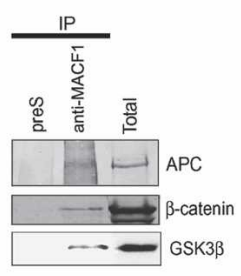

$\mathrm{F}$

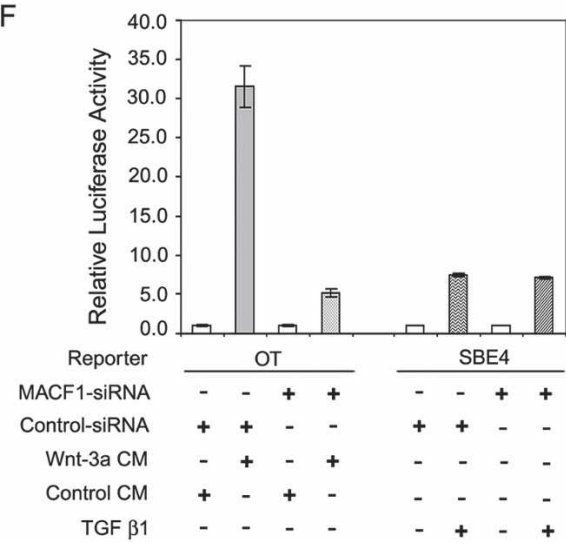

C

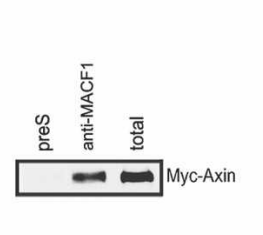

D

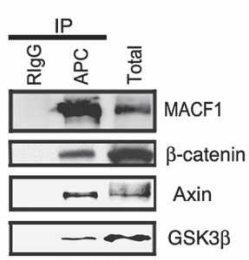

E
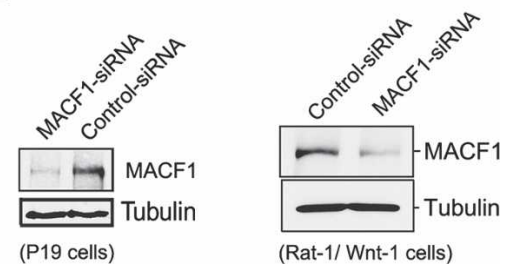

G

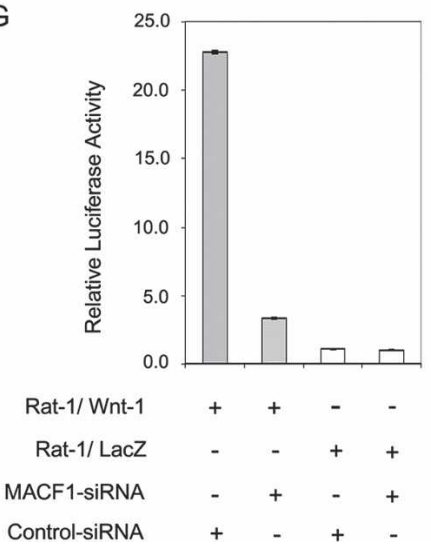

$\mathrm{H}$

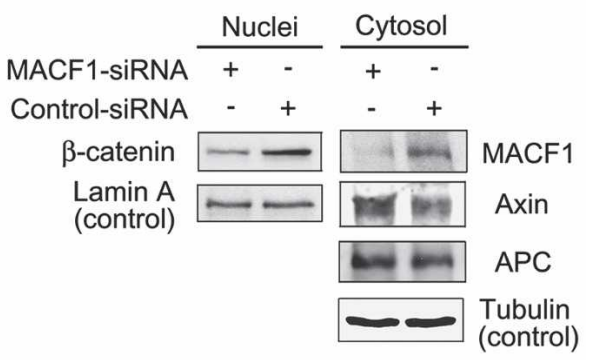

Figure 3. MACF1 in the Wnt/ $\beta$-catenin signaling pathway. $(A, B)$ Cell lysates from PC12 cells $(A)$ and Rat-1/LacZ cells $(B)$ were immunoprecipitated (IP) by anti-MACF1 antibody, and the blots were probed with anti-APC, anti-Axin, anti- $\beta$-catenin, and antiGSK3 $\beta$ antibodies. (preS) Immunoprecipitation control by preimmune serum; (Total) total lysate. (C) Cell lysates from c-myc-Axintransfected PC12 cells were immunoprecipitated by anti-MACF1 antibody, and the blot was probed with anti-c-Myc antibody. $(D)$ Cell lysates from PC12 cells were immunoprecipitated by anti-APC antibody, and the blots were probed for MACF1, $\beta$-catenin, Axin, and GSK3 $\beta$. (RigG) Immunoprecipitation control by rabbit IgG. (E) Knockdown of MACF1 protein by siRNA in Wnt-1-transfected-P19 cells (left) and Rat-1/Wnt-1 cells (right). Cell lysates were subjected to Western blots with anti-MACF1 antibody (MACF1) and anti- $\beta$ tubulin antibody (Tubulin). (F) P19 cells were transfected with MACF1 siRNA or control vector and reporter constructs pGL3-OT (OT) or pSBE4-luc (SBE4), and then treated with Wnt-3a-conditioned medium, control medium, or TGF 1 (200 pM). The lysates were subjected to dual luciferase assays. Each data point was done in triplicate. $(G)$ Rat-1/Wnt-1 or Rat-1/LacZ cells were transfected with MACF1 siRNA vector or control vector, and reporter constructs. Assay conditions were the same as in $F$. $(H)$ Rat-1/Wnt-1 cells were transfected with MACF1 siRNA or control vector, and nuclear (Nuclei) and cytosolic (Cytosol) fractions were isolated. The cytosolic fraction was probed for MACF1, Axin, and APC, while the nuclear fraction was probed for $\beta$-catenin. $\beta$-tubulin (Tubulin) and Lamin A were used as loading controls for cytosol and nuclear fractions, respectively.

3G). To determine whether this decrease in TCF $/ \beta$ catenin-mediated transcriptional activity was the result of reduced $\beta$-catenin levels in the nucleus, we isolated the cytosolic and nuclear fractions of Rat-1/Wnt-1 cells that were transfected with either MACF1 siRNA vector or control vector for Western blotting. As shown in Figure $3 \mathrm{H}$, the amount of $\beta$-catenin in the nucleus of MACF1 knockdown cells was reduced compared with that of the control cells. This reduction of nuclear $\beta$-catenin could account for the decrease of luciferase activity in the reporter assays. These data indicated that MACF1 had a role as a positive downstream regulator of the Wnt/ $\beta$-catenin signaling pathway. We found no significant differences in the levels of APC in the cytosolic fraction; however, the amount of Axin increased after treatment with the MACF1 siRNA vector, suggesting that MACF1 could be involved in the control of Axin stability.

\section{MACF1 acts upstream of GSK3 $\beta$}

Lithium chloride inhibits GSK3 $\beta$ kinase activity and activates Wnt-responsive gene expression. To determine whether the role of MACF1 in Wnt/ $\beta$-catenin signaling is upstream or downstream of GSK3 $\beta$, we knocked down MACF1 protein with siRNA in cells transfected with TCF-luciferase reporter constructs and treated the cells with LiCl. As shown in Figure 4A, TCF/ $\beta$-catenin-mediated luciferase activity was induced $\sim 20$-fold in P19 cells transfected with control siRNA vector after $\mathrm{LiCl}$ treatment. The same induction level of TCF/ $\beta$-catenin-mediated luciferase activity also occurred in MACF1-knockdown P19 cells with $\mathrm{LiCl}$ treatment. Similar results were obtained in the Rat-1/LacZ cells (data not shown). These data suggested that MACF1 acted upstream of GSK3 $\beta$ in the canonical Wnt signaling pathway.

\section{MACF1 and the Axin complex translocate to the cell} membrane upon Wnt stimulation

In the presence of Wnt, Axin is translocated from the cytoplasm to the cell membrane, where it binds to the Wnt coreceptor LRP5 (Mao et al. 2001). We wanted to determine whether MACF1 and the other components of the complex were also translocated to the cell membrane 
Chen et al.

A

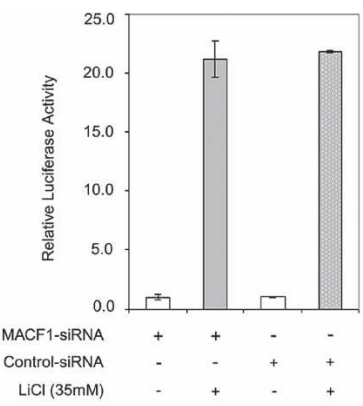

B

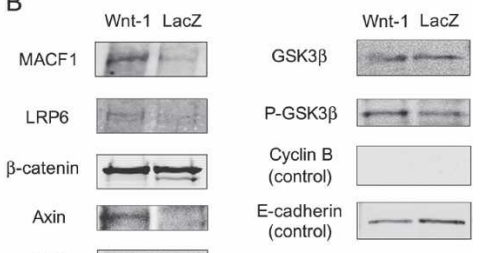

APC

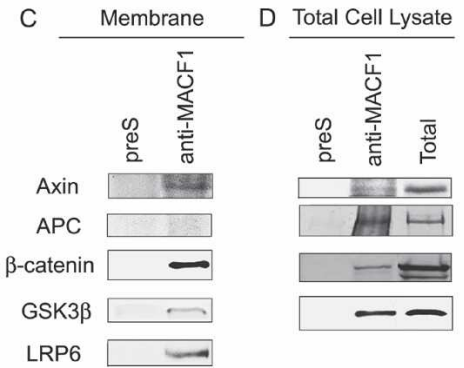

Figure 4. MACF1 acts upstream of GSK3 $\beta$ and associates with the Axin complex at the cell membrane upon Wnt stimulation. (A) TCF/ $\beta$-catenin transcriptional activity of MACF1 knockdown P19 cells after $\mathrm{LiCl}$ treatment to inhibit GSK3 $\beta$ activity. Cell lysates were subjected to dual luciferase assays. $\mathrm{LiCl}$ treatment is in gray, while no treatment is in white. $(B)$ Membrane fractions were isolated from Rat-1/Wnt-1 or Rat-1/LacZ cells, and the blots were probed for MACF1, LRP6, $\beta$-catenin, Axin, APC, GSK3 $\beta$, and phosphorylated GSK3 $\beta$ (P-GSK3 $\beta$ ). Cytosolic cyclin B and membranous E-cadherin served as control. $(C)$ The membrane fraction was isolated from Rat-1/Wnt-1 cells and immunoprecipitated by anti-MACF1 antibody, and the blots were probed for indicated proteins. (preS) Immunoprecipitation control by preimmune serum. Note that all the Axin complex components, except APC, were immunoprecipitated by antiMACF1. (D) Total cell lysates from Rat-1/Wnt-1 cells were immunoprecipitated by anti-MACF1 antibody, and the blots were probed for indicated proteins. The blots of the total cell lysates (Total) are shown as comparison.

upon Wnt stimulation. We compared the relative amounts of these components by Western blots in the membrane extracts of Rat-1/Wnt-1 and Rat-1/LacZ cells. As shown in Figure 4B, Rat-1/Wnt-1 cells had more MACF1, LRP6, and phosphorylated GSK3 $\beta$ (inactive form) in the membrane fraction than Rat-1/LacZ cells. Axin was present in the membrane extract from the Rat1/Wnt-1 cells, but was absent in the membrane fraction from the control Rat-1/LacZ cells. There were similar amounts of $\beta$-catenin and GSK $3 \beta$ in the membrane fractions of both types of cells. Surprisingly, we did not de- tect any APC in the membrane fraction of Rat-1/Wnt-1 cells. Our results indicated that MACF1, Axin, $\beta$-catenin, GSK3 $\beta$, and LRP6, but not APC, were present in the membrane fraction of Wnt-1-expressing cells. Immunoprecipitation experiments with anti-MACF1 antibody on the membrane extract of Rat-1/Wnt-1 cells showed that Axin, LRP6, $\beta$-catenin, and GSK3 $\beta$, but not APC coimmunoprecipitated with MACF1 (Fig. 4C). These results indicated that these Wnt signaling components formed a complex at the cell membrane. To show that APC was part of the cytoplasmic Axin complex upon Wnt stimulation, total cell lysates of Rat-1/Wnt-1 cells were used for immunoprecipitation with antiMACF1 antibody. The results showed that anti-MACF1 antibody coimmunoprecipitated APC, in addition to Axin, $\beta$-catenin, and GSK3 $\beta$ (Fig. 4D). Thus it appeared that APC was released from the MACF1, Axin, GSK3 $\beta$, and $\beta$-catenin complex, when this complex moved to the cell membrane upon Wnt stimulation.

\section{Identification of MACF1 domains that interact with the Axin complex}

We made a series of MACF1 deletion constructs to determine which region on MACF1 interacted with the Wnt signaling complex (Fig. 5A) and tested the binding of each of them with proteins in the Axin complex by coimmunoprecipitation studies. All the proteins we tested bound to a region on MACF1 from the C terminus of the plakin domain to the end of the spectrin repeats, with stronger binding to the SR0 region (Fig. 5A; Supplementary Figs. S2-S6). As shown in Figure 5A, the binding patterns of Axin, $\beta$-catenin, GSK3 $\beta$, and APC to the different fragments of MACF1 were very similar. Axin is known to be a scaffolding protein that interacts with APC, $\beta$-catenin, and GSK3 $\beta$ in different regions (Fig. 5B). We inferred that the binding of MACF1 to APC, $\beta$-catenin, and GSK3 $\beta$ could be through Axin. To test whether there was direct binding between MACF1 and Axin, SR0-His, and GST-Axin C (C terminus of Axin; see below for the mapping of Axin-binding site on MACF1), proteins were purified from bacteria for GST pull-down assays. The results showed that SR0-His bound directly to GST-Axin C, but not to GST (Fig. 5B). We also mapped the binding region of Axin to MACF1 protein. We found that two deletion clones Axin (810-956) and Axin (531956) coimmunoprecipitated with MACF1 (Fig. 5B; Supplementary Fig. S7). Therefore, the binding site of Axin to MACF1 was located on the region containing amino acids 810-956.

Anti-MACF1 antibody immunoprecipitated LRP6 in the membrane extract of Rat-1/Wnt-1 cells (Fig. 4C), suggesting that MACF1 might interact directly with LRP6. A GST pull-down assay was done using bacterially purified GST-LRP6C (intracellular domain of LRP6) and SR0His proteins. SR0-His bound directly to GST-LRP6C (Fig. 5B). Therefore, both Axin and LRP6 could interact directly with the 74-kDa SR0 fragment of MACF1. Competition assays showed that LRP6 and Axin could bind to the MACF1-SR0 domain simultaneously (Supplemen- 
A

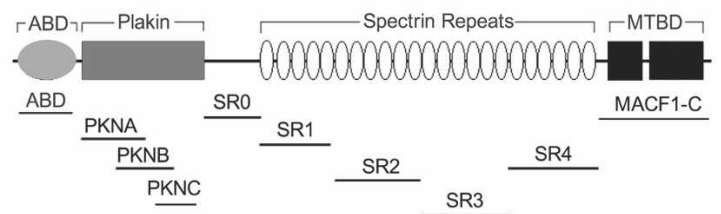

\begin{tabular}{|c|c|c|c|c|c|c|c|c|c|c|}
\hline $\begin{array}{c}\text { Deletion } \\
\text { Fragment } \\
\text { (Amino acids }\end{array}$ & $\begin{array}{l}A B D \\
(61-348)\end{array}$ & $\begin{array}{c}\text { PKNA } \\
(414-927)\end{array}$ & $\begin{array}{l}\text { PKNB } \\
(660-1130)\end{array}$ & \begin{tabular}{|l} 
PKNC \\
$(831-1282)$
\end{tabular} & $\begin{array}{c}\text { SR0 } \\
(1544-2119)\end{array}$ & $\begin{array}{c}\text { SR1 } \\
(2120-2837\end{array}$ & $\begin{array}{c}\text { SR2 } \\
(2838-3491)\end{array}$ & $\begin{array}{c}\text { SR3 } \\
(3492-4148)\end{array}$ & $\begin{array}{c}\text { SR4 } \\
4149-4822\end{array}$ & $\underset{(4865-5327}{\mathrm{C}}$ \\
\hline Axin & - & - & - & + & +++ & ++ & + & + & ++ & - \\
\hline LRP6 & - & - & + & ++ & +++ & + & + & - & - & - \\
\hline$\beta$-catenin & - & - & - & + & +++ & ++ & + & + & + & - \\
\hline GSK3 $\beta$ & - & - & - & + & +++ & ++ & + & - & +++ & - \\
\hline APC & - & - & ++ & +++ & ++ & + & + & + & ++ & + \\
\hline
\end{tabular}

B
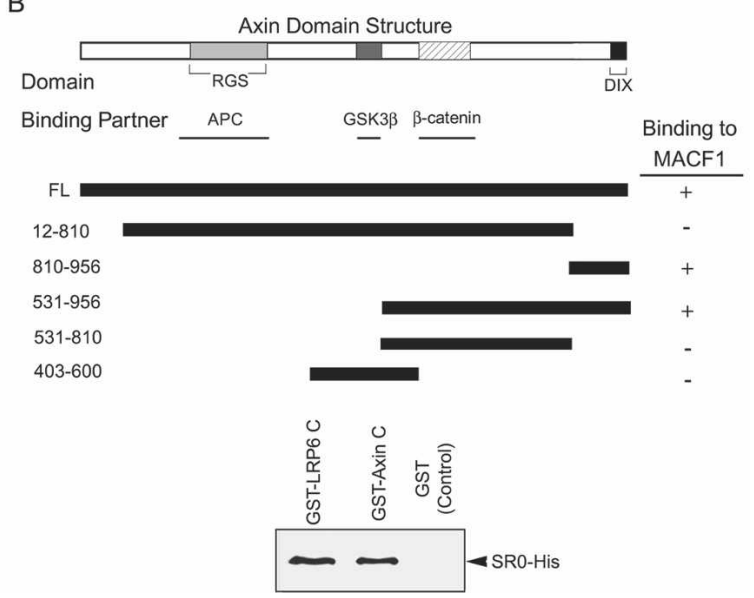

Figure 5. Mapping the interactions between MACF1 and Wnt signaling proteins. (A) Identification of MACF1 domains that interact with Wnt signaling proteins. The top panel shows the domain organization of MACF1. The relative positions of the truncated constructs are indicated. Interactions between MACF1 and Wnt signaling proteins were determined by coimmunoprecipitation experiments. The degree of binding is symbolized by the number of + signs; (-) no binding. (B) Dissection of the interactions between Axin and MACF1. The diagram shows the domain structure of Axin and the location of the binding regions for other proteins. + and - indicate the ability of these constructs to coimmunoprecipitate with anti-MACF1. (Bottom panel) MACF1 deletion fragment SR0 binds directly to LRP6C and Axin C. GST-pull-down assays were performed by incubating SR0-his (purified SR0 fragment with a C-terminal 6x his tag) with GST-LRP6C (the intracellular domain of LRP6 fused with GST protein; purified), GST-Axin C (C terminus of Axin fused with GST; purified), or GST proteins alone (GST; control). The blot was probed with anti-his antibody.

tary Fig. S8). As Axin can bind LRP5 directly (Mao et al. 2001), the interaction between MACF1 and LRP6 might stabilize the complex at the cell membrane.

\section{MACF1 is involved in Axin translocation}

Knockdown of MACF1 led to an increase of Axin in Rat1/Wnt-1 cells (Fig. 3H), suggesting that MACF1 may be involved in the control of Axin stability. To investigate the role of MACF1 in Axin stability, we expressed different MACF1 deletion constructs (Fig. 5A) in Rat-1/ Wnt- 1 cells, and determined the levels of total Axin by Western blotting. Overexpression of MACF1 deletion fragments of HA-SR0 (Fig. 6A) resulted in an increase of Axin by 2.6-fold. This result was similar to the effect of MACF1 knockdown by siRNA on Axin stability (Fig. $3 \mathrm{H})$. Hence, in this assay, HA-SR0 functioned as a dominant-negative construct, probably by removing endogenous MACF1 from the Axin complex.

Upon Wnt stimulation, Axin is translocated from the cytoplasm to the cell membrane, where it binds to LRP5 and is subsequently degraded (Mao et al. 2001). There are two possible mechanisms by which MACF1 could affect Axin stability: (1) MACF1 could be involved in the translocation of Axin to the cell membrane, or (2) MACF1 may be involved in Axin degradation at the cell membrane. We transfected Rat-1/Wnt-1 and P19 cells treated with Wnt-3a with MACF1 siRNA or control siRNA and determined the amounts of Axin at the cell membrane and examined the interaction of LRP6 with Axin. If MACF1 is involved in translocating Axin to the cell membrane, knockdown of MACF1 should result in a reduction of Axin at the cell membrane and a decrease in Axin bound to LRP6. If MACF1 is involved in Axin degradation after translocation of Axin to the cell membrane, the opposite should occur. We found that knockdown of MACF1 reduced the amount of Axin on the cell membrane to $26 \%$ of control in Wnt3a-treated P19 and to $52 \%$ of control in Rat- $1 /$ Wnt-1 cells (Fig. $6 \mathrm{~B}$ ). The amount of Axin immunoprecipitated by LRP6 in Rat-1/ Wnt-1 cells was decreased by MACF1 siRNA treatment (Fig. 6C), as well as overexpression of HA-SR0 (Fig. 6D). These results were consistent with a role for MACF1 in translocating Axin to the cell membrane. To confirm that HA-SR0 could act in a dominant-negative manner, Rat-1/Wnt-1 cells and P19 cells were transfected with HA-SR0 together with TCF- luciferase reporter constructs. Luciferase activity was reduced in both Rat-1/ Wnt-1 cells and in P19 cells treated with Wnt-3a-conditioned medium when they were transfected with the HA-SR0 constructs compared with controls (Fig. 6E,F). These data also suggested that MACF1 was required for the translocation of Axin and its associated proteins to the cell membrane, and that this process was necessary for Wnt/ $\beta$-catenin signaling.

Inhibition of Wnt-1-induced $T$ gene expression by MACF1 knockdown provides an explanation for the defects in MACF1-null embryos

$T$ (Brachyury) has been regarded as the key gene controlling mesoderm formation in early embryonic development (Cunliffe and Smith 1992; O'Reilly et al. 1995; Yamaguchi et al. 1999a). It is induced by Wnt/ $\beta$-catenin signaling (Yamaguchi et al. 1999b; Lako et al. 2001) and has a TCF $/ \beta$-catenin-binding site in its promoter (Arnold et al. 2000). In $M A C F 1^{-1-}$ mice, there was a complete absence of immunostaining with an antibody to $\mathrm{T}$, con- 
Chen et al.

A

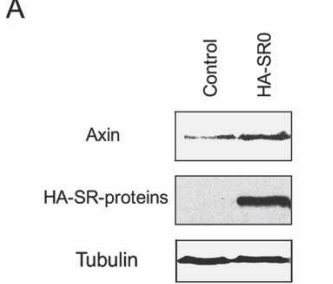

B

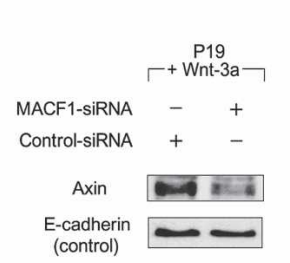

C

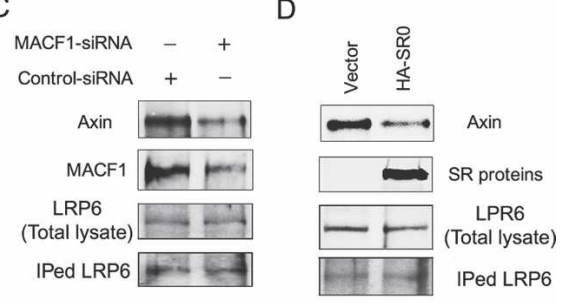

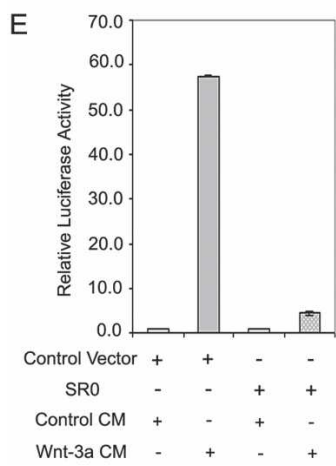

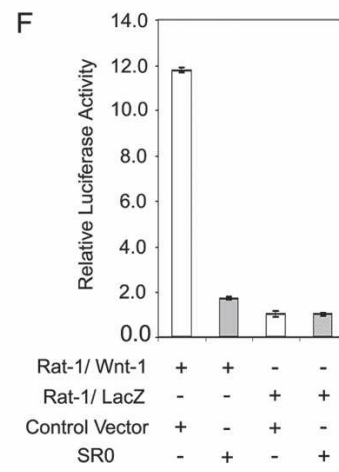

G

$\mathrm{H}$

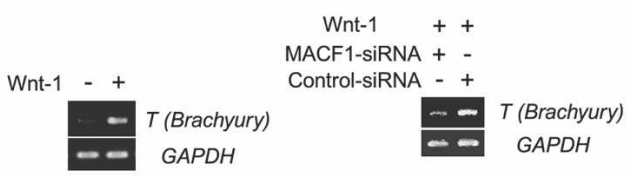

Figure 6. Involvement of MACF1 in Axin translocation to the cell membrane and reduction of $T$ (Brachyury) gene expression in MACF1 knockdown P19 cells transfected with Wnt-1. (A) Overexpression of MACF1 deletion fragment SR0 resulted in an increase of Axin stability. Rat-1/Wnt-1 cells were transfected with HA-SR0 or control vectors (Control), lysed, and processed for Western blotting using anti-Axin (Axin), anti-HA (HA-SR-proteins), and anti-tubulin (Tubulin) antibodies. (B) Knockdown of MACF1 decreased the amount of Axin at the cell membrane. Rat-1/Wnt-1 cells and Wnt-3a-treated P19 cells were transfected with MACF1 siRNA vector or control vector. Membrane fractions were isolated, and the blot was probed for Axin. E-cadherin served as a control for membrane proteins. (C) Knockdown of MACF1 decreased the binding of Axin to LRP6. Rat-1/Wnt-1 cells were transfected with MACF1 siRNA or control vectors. Cell lysates were immunoprecipitated by anti-LRP6 antibody, and the blot was probed with anti-Axin (top panel) and anti-LRP6 (IPed LRP6; bottom panel) antibodies. Western blotting of the total cell lysate with anti-LRP6 antibody (LRP6; lower middle panel) and knockdown of MACF1 is shown by anti-MACF1 antibody (upper middle panel). (D) Overexpression of MACF1 deletion fragment SR0 reduced the binding of Axin to LRP6. Rat-1/Wnt-1 cells were transfected with MACF1 deletion cDNA clone HA-SR0 or control vector. Cell lysate was immunoprecipitated by anti-LRP6 antibody, and the blot was probed with anti-Axin (top panel) and anti-LRP6 (IPed LRP6; bottom panel) antibodies. Expression of SR and endogenous LRP6 proteins was shown in the blots from total cell lysate probed with anti-HA (SR proteins; upper middle panel) and anti-LRP6 (lower middle panel) antibodies. (E) Reduction of TCF/ $\beta$-catenin transcriptional activity in Wnt-3a-treated P19 cells expressing SR0 proteins. P19 cells were transfected with reporter constructs, and HA-SR0 or control constructs, then treated with Wnt-3a-conditioned medium (Wnt-3a CM; in gray) or control medium (Control CM; in white). Cell lysis, dual luciferase assay, and data processing were as described in Figure 3F. (F) Reduction of TCF/ $\beta$-catenin transcriptional activity in Rat-1/Wnt-1 cells expressing SR0 proteins. Rat-1/Wnt-1 cells were transfected with reporter constructs, HA-SR0, or control constructs, and assayed for luciferase activity. (Control) White bar; (SR0) gray bar. (G) $T$ (Brachyury) gene expression could be induced by expressing Wnt-1 in P19 cells. P19 cells were transfected with Wnt-1, and T (Brachyury) gene expression was assessed by RT-PCR. GAPDH served as an internal control. (H) T (Brachyury) gene expression was decreased in MACF1-knocked-down P19 cells. P19 cells were transfected with MACF1-siRNA vector and Wnt-1 or control siRNA vector and Wnt-1 (treatment symbolized by + ), then $T$ (Brachyury) gene expression was assessed by RT-PCR as described in the Materials and Methods. GAPDH served as an internal control.

sistent with an effect of MACF1 on the Wnt signaling pathway. $T$ gene expression was dramatically induced in the P19 cells transfected with Wnt-1 (Fig. 6G), but treatment with MACF1 siRNA substantially decreased $T$ gene expression (Fig. 6H). Quantification by real-time RT-PCR showed a fourfold decrease in T mRNA levels in the Wnt-1 and MACF1 siRNA-transfected P19 cells as compared with Wnt-1 and control siRNA-transfected cells (data not shown). These results indicated that MACF1 is involved in the Wnt/ $\beta$-catenin-induced $T$ gene expression and provided an explanation for the lack of $\mathrm{T}$ staining in $\mathrm{MACF1}^{-/-}$embryos. As $\mathrm{T}$ can specify the mesoderm formation during early embryo development, $M A C F 1^{-1-}$ embryos would exhibit defects in the formation of the primitive streak (nascent mesoderm) and me- soderm in the absence of T. As a result, $M A C F 1^{-/-} \mathrm{em}$ bryos had a similar phenotype as Wnt- $3^{-/-}$and LRP5/6 double-knockout mice.

\section{Discussion}

MACF1 is a member of the (spectra) plakin family and has been shown to be a cytoskeletal linker protein that can interact with actin and microtubules in cultured cells (Leung et al. 1999). To study the function(s) of MACF1 in vertebrates, we created $M A C F 1^{-/-}$mice (Fig. $1 \mathrm{~A}-\mathrm{C})$. $\mathrm{MACF}^{+/-}$mice were apparently normal and fertile, but $\mathrm{MACF1}^{-/-}$mice died early during embryogenesis (Fig. 1D) with development halted at around E7.5. In contrast, $B P A G 1^{-/-}$mice survive until weaning and suf- 
fer from sensory neuron degeneration, even though both BPAG1 and MACF1 are expressed early in development (Fig. 1H). These results suggest that BPAG1 and MACF1 do not have completely overlapping functions during embryogenesis. Further studies by histological and tissue-specific marker analyses suggested that $M A C F 1^{-/-}$ embryos were able to form the neural plate and anterior visceral endoderm (AVE), but not the primitive streak, node, and mesoderm (Fig. 2). During gastrulation, the localization of the primitive streak (nascent mesoderm) defines the posterior side of the embryo, and the anterior is on the opposite side of the epiblast. As epiblasts move into the primitive streak, they undergo an epithelial-tomesenchymal transition and subsequently move away from the primitive streak to form the mesoderm layer. Therefore, the absence of a primitive streak would lead to the lack of mesoderm formation. The node is not essential for the induction of neural tissues (Dufort et al. 1998), and the current model for anterior neural patterning emphasizes the importance of AVE as a source of inductive signals for initiating anterior neural specification of the adjacent epiblast (Beddington and Robertson 1999). In agreement with this notion, we found that in the presence of AVE, the neural plate still formed in $M A C F 1^{-/-}$embryos, despite the absence of a node at the distal tip. The lack of a node in $M A C F 1^{-1-}$ embryos would lead to defects in the anterior-posterior axis formation, since the node is essential for anterior-posterior axis formation. The presence of the neural plate and AVE and the lack of primitive streak in $M A C F 1^{-1-}$ embryos revealed that they display a "head-without-trunk" phenotype. Therefore, MACF1 is required for posterior formation during early embryogenesis.

Wnt-3 is the earliest-acting Wnt in mammals, and it triggers the canonical signaling cascade. Wnt-3 is important in posterior pattern formation, since $W n t-3^{-/-}$mice showed deficits in the formation of the primitive streak, node, and mesoderm (Liu et al. 1999). A similar phenotype has also been observed in the Wnt coreceptor LRP5/6 double-knockout mice. Morphologically, $M A C F 1^{-/-}$embryos were similar to $W n t-3^{-/-}$and LRP5/6 double-knockout embryos. $M A C F 1^{-/}$embryos failed to express markers of the primitive streak, node, and mesoderm ( $\mathrm{T}$ staining), similar to $W n t-3^{-/-}$mice and LRP5/6 double-knockout mutant embryos (Fig. 2). Anterior patterning is correctly established in Wnt-3, LRP5/6, and MACF1 mutant embryos as indicated by the expression and localization of the AVE marker (Lhx1). These results suggested that MACF1 function may be required for Wnt-3 signaling in establishing the posterior patterning of the embryo. However, the neuroectoderm did not form in Wnt-3-null embryos, but was present in both $M A C F 1^{-1-}$ and LRP5/6 double-null embryos. It is possible that Wnt-3 signaled through an unknown mechanism for neuroectoderm development. Nonetheless, the similarity of MACF1 to Wnt-3 and LRP5/6 mutant embryos suggested that MACF1 could act downstream in the canonical Wnt signaling pathway.

Our biochemical studies showed that MACF1 associated with the core canonical Wnt protein complex con- taining Axin, APC, GSK3 $\beta$, and $\beta$-catenin (Figs. 3A-D, 4D). Analysis of the binding domain of MACF1 to Axin, APC, GSK3 $\beta$, and $\beta$-catenin also supported the idea that MACF1 could bind to these Wnt components and form a complex because their binding patterns to MACF1 were very similar (Fig. 5A). The results of the TCF/ $\beta$-catenin transcriptional activity assays confirmed the involvement of MACF1 in Wnt/ $\beta$-catenin signaling pathway. Knockdown of MACF1 by siRNA reduced the Wnt-induced TCF/ $\beta$-catenin transcriptional activity in Wnt-3atreated P19 cells and Rat-1/Wnt-1 cells (Fig. 3E-G). The reduction in $\mathrm{TCF} / \beta$-catenin transcriptional activity was accompanied by reduction of $\beta$-catenin in the nucleus (Fig. 3H). Similar results were obtained by overexpression of a dominant-negative mutant version of MACF1 in both Rat-1/Wnt-1 and Wnt-3a-treated P19 cells (Fig. $6 \mathrm{E}, \mathrm{F}) . T$ (Brachyury) is a target gene of the $\mathrm{Wnt} / \beta$-catenin signaling, and its promoter has a TCF $/ \beta$-catenin-binding site (Arnold et al. 2000). Our results showed that T expression was reduced in MACF1-siRNA-transfected P19 cells expressing Wnt-1 (Fig. 6G,H). These results were consistent with our observation that $\mathrm{T}$ staining was $\mathrm{ab}$ sent in E7.5 $\mathrm{MACF1}^{-1-}$ embryos (Fig. 2E,F). Taken together, these data indicated that MACF1 was a component of the Wnt/ $\beta$-catenin signaling pathway.

$\mathrm{TCF} / \beta$-catenin transcriptional activity did not change in MACF1 knockdown cells as compared with control cells after $\mathrm{LiCl}$ treatment (Fig. 4A), indicating that MACF1 functioned upstream of GSK3 $\beta$ in the Wnt $\beta$ catenin signaling pathway. We found that Axin formed a complex in the cytosol with $\beta$-catenin, GSK3 $\beta$, APC, and MACF1, and upon Wnt stimulation proteins in this complex (except APC) translocated to the cell membrane, where they interacted with LRP5/6 (Fig. 4B-D). APC has been shown to promote Axin complex assembly in the cytoplasm (Cliffe et al. 2003) and may dissociate from the MACF1-Axin complex at the time of translocation.

MACF1 bound to a region of Axin (amino acids 810956) that was distinct from the binding sites on Axin for APC, GSK3 $\beta$, and $\beta$-catenin (Fig. 5B). Therefore, the binding of MACF1 to Axin would not interfere with the binding of Axin to these other proteins. The binding patterns of the Wnt signaling components to MACF1 fragments were similar (Fig. 5A), and the SR0 fragment of MACF1 bound directly to an Axin fragment (Fig. 5B), suggesting that the other Wnt signaling proteins interacted with MACF1 through Axin.

The levels of Axin are reduced by Wnt stimulation (Willert et al. 1999; Yamamoto et al. 1999), Wg overexpression (Tolwinski et al. 2003), and Lrp $5 \Delta \mathrm{N}$ overexpression (Mao et al. 2001) in mammalian and Drosophila cells, suggesting that inhibition of Wnt $/ \beta$-catenin signaling would increase the total amount of Axin. The increased Axin levels that we observed after MACF1 knockdown (Fig. $3 \mathrm{H}$ ) or by overexpression of the SR0 dominant-negative mutant of MACF1 in Rat-1/Wnt-1 cells (Fig. 6A) are consistent with this idea, since these treatments should lead to inhibition of Wnt signaling. Based on these results, MACF1 appears to regulate Axin stability. Upon Wnt stimulation, Axin is translocated 
Chen et al.

A

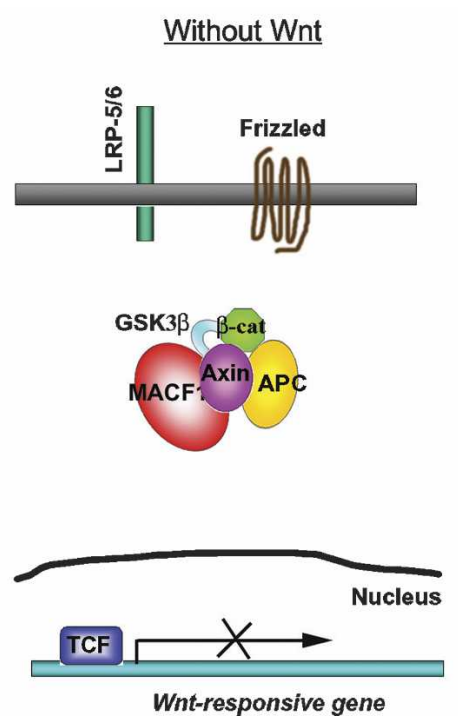

B With Wnt

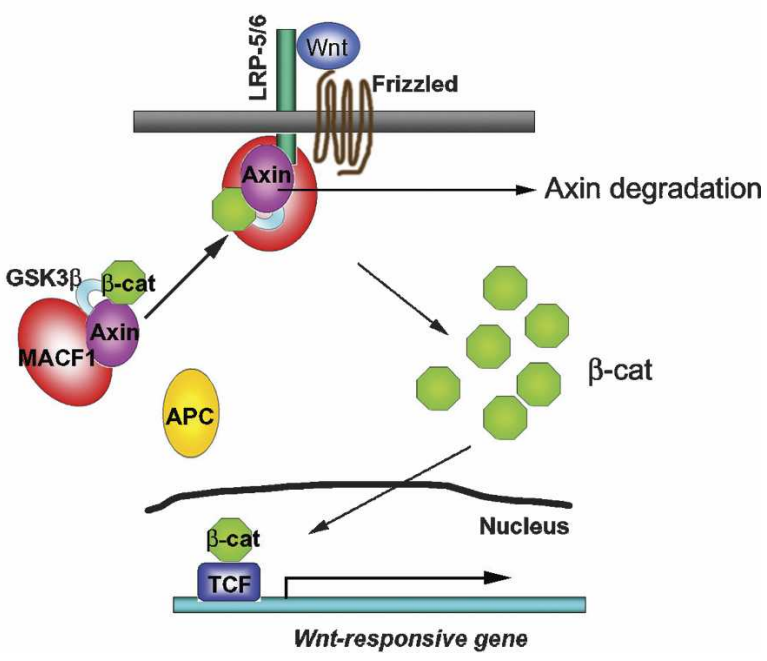

Figure 7. A model for the involvement of MACF1 in the Wnt/ $\beta$-catenin signaling pathway. (A) Without Wnt, MACF1 (red) binds to a protein complex containing Axin (purple), APC (yellow), $\beta$-catenin (green), and GSK3 $\beta$ (light blue). There is no expression of the TCF (blue) controlled genes due to the degradation of $\beta$-catenin after phosphorylation by GSK3 $\beta$. $(B)$ Wnt activates its receptor frizzled and its coreceptor LRP-5/6. MACF1 is involved in the translocation of the complex containing Axin, $\beta$-catenin, and GSK3 $\beta$ but not APC from the cytosol to the cell membrane, where Axin and MACF1 bind to LRP-5/6. Subsequently, GSK3 $\beta$ is inactivated by phosphorylation, Axin is degraded, and $\beta$-catenin is released and enters the nucleus, where it can activate the Wnt-responsive genes.

from the cytoplasm to the cell membrane and degraded. MACF1 could either be involved in Axin translocation or Axin degradation after translocation to the cell membrane to regulate Axin levels. Our data support the former mechanism based on the following observations: (1) Knockdown of MACF1 decreased the amount of Axin at the cell membrane upon Wnt stimulation (Fig. 6B); (2) knockdown of MACF1 decreased the binding of Axin to LRP6 in Rat-1/Wnt-1 cells (Fig. 6C); and (3) overexpression of the SR0 dominant-negative mutant decreased the binding of Axin to LRP6 in Rat-1/Wnt-1 cells (Fig. 6D). We also showed that the SR0 fragment of MACF1 was able to bind directly to the intracellular domain of LRP6 (Fig. 5B). We concluded that MACF1 is required for Axin translocation to the cell membrane and binds to LRP6 upon Wnt stimulation. This hypothesis could also explain the similarity of $M A C F 1^{-/-}$embryos to LRP5/6 double-knockout embryos. The reason for the lack of Wingless-related phenotypes in shot mutant flies is less clear, but could be due to the relative scarcity of shot mutant alleles compared with the size of the shot gene.

Taken together, we propose the model depicted in Figure 7 describing the involvement of MACF1 proteins in the canonical Wnt signaling pathway. We postulate that in the absence of Wnt, MACF1 interacts with a complex that includes Axin, GSK3 $\beta$, $\beta$-catenin, and APC. In this complex, $\beta$-catenin is phosphorylated by GSK3 $\beta$ and degraded (Fig. 7A). Upon Wnt binding to its receptor and coreceptor, MACF1 is involved in the translocation of the complex to the cell membrane, where it also binds to the coreceptor LRP5/6. Axin is subsequently degraded, GSK3 $\beta$ is inhibited, and $\beta$-catenin is released from the complex and translocated to the nucleus, where it ini- tiates TCF/LEF-dependent transcription (Fig. 7B). SR0 acted as a dominant-negative construct, but could bind LRP6 and Axin simultaneously. This result suggests that other proteins not depicted in Figure 7 mediate the translocation of the MACF1-Axin protein complex to the membrane.

In summary, we generated MACF1-knockout mice, which lack the formation of the primitive streak, node, and mesoderm during gastrulation, reminiscent of Wnt$3^{-/-}$mice and LRP5/6 double-knockout mice. Our results indicated that MACF1 is involved in the Wnt signaling pathway and functions as a positive regulator in the translocation of Axin and its associated complex from the cytoplasm to the cell membrane, an indispensable step to transduce signaling upon Wnt stimulation.

\section{Materials and methods \\ Generation of MACF1-knockout mice}

A mouse MACF1 genomic DNA clone that contains the plakin domain exons was isolated by screening a $129 / \mathrm{Sv}$ mouse genomic library (Stratagene) with a mouse MACF1 cDNA probe. The targeting vector was constructed by replacing part of the plakin domain with a neomycin expression cassette (Fig. 1A). CSL3 ES cells (transgenic facility, Columbia University) were electroporated with the linearized targeting vector and selected for neomycin-resistant colonies. Colonies were expanded and screened by Southern blots. Two positive clones were expanded and microinjected into $\mathrm{C} 57 \mathrm{BL} / 6 \mathrm{~J}$ blastocysts. Male chimeras were bred with C57BL/6J females to establish F1 progeny.

\section{Genotyping}

Mouse genomic DNA was digested with the restriction enzyme $\mathrm{XbaI}$, resolved by $0.8 \%$ agarose gels, transferred onto nylon 
membranes (Bio-Rad), and hybridized with a MACF1 probe. Hybridization was carried out at $60^{\circ} \mathrm{C}-65^{\circ} \mathrm{C}$ in hybridization buffer (6x SSC, $2 \times$ Denhardt's reagent, $0.1 \%$ SDS) overnight. The membranes were washed two times with $1 \times$ SSC and $0.1 \%$ SDS at room temperature, and three times with $0.2 \times$ SSC and $0.1 \%$ SDS at $60^{\circ} \mathrm{C}-65^{\circ} \mathrm{C}$. Membranes were blot-dried and exposed to film. Genomic PCR was also performed for genotyping. DNA samples from yolk sac or embryos were incubated in $30 \mu \mathrm{L}$ of lysis buffer $150 \mathrm{mM}$ Tris at $\mathrm{pH} 8.0,0.5 \%$ Triton X-100, $200 \mu \mathrm{g}$ of proteinase $\mathrm{K}$ per milliliter) at $50^{\circ} \mathrm{C}$ overnight and heated to $95^{\circ} \mathrm{C}$ for 5 min before PCR reaction. The PCR primers for genotyping were forward, KO-F, 5'-GAGACTTTGGCCAAGGTATACAT CTCTG-3' ${ }^{\prime}$ reverse, KO-R, 5' ${ }^{\prime}$-CAAATCCAAGTTTGGCTCTG ATGCTGGG-3'. The PCR cycling parameters were $2 \mathrm{~min}$ of denaturation at $95^{\circ} \mathrm{C}$, and then 30 cycles of $95^{\circ} \mathrm{C}$ for $20 \mathrm{sec}$, $69^{\circ} \mathrm{C}$ for $30 \mathrm{sec}$, and $72^{\circ} \mathrm{C}$ for $4 \mathrm{~min}$, followed by $72^{\circ} \mathrm{C}$ for $10 \mathrm{~min}$ using Pfu turbo Taq DNA polymerase (Stratagene).

\section{$R T-P C R$}

RT-PCR was performed using OneStep RT-PCR kit (Qiagen). The gene-specific primer pairs were MACF1 (located in plakin domain), 5'-CCAAAGCGAGTTGGCTCAGCAGACGGA AC-3' and 5'-CCTCTTGTTCTCTGCCAGCTCTGTCGCTGC-3'; BPAG1 (located in plakin domain), 5'-CATGCATTGGAAGAC GAGTTGCAGAAAGC-3' and 5'-AACGAGGTCTGCTGAGCT CTGTATCCGC-3'; BPAGla/b (located in C terminus GAR domain), 5'-CTACAGTGGGCGGAAACCACACTGACCGAG$3^{\prime}$ and 5'-TCACCAGCAGGTTAACCCTGGGGTTCTTGG-3'; GAPDH (accession no. M32599), 5' -ATGGTGAAGGTCGGTG TGAACGGATTTG-3' and 5'-GTGGTGAAGACACCAGTAG ACTCCACGAC-3'. One microgram of total RNAs from mouse E7, E11, E15, and E17 embryos (BD Clontech) was used for each reaction. The RT-PCR cycling parameters included an RT step at $50^{\circ} \mathrm{C}$ for $40 \mathrm{~min}$, followed by an incubation step at $95^{\circ} \mathrm{C}$ for $15 \mathrm{~min}, 30$ cycles ( 25 cycles for GAPDH gene) at $94^{\circ} \mathrm{C}$ for $20 \mathrm{sec}$, $64^{\circ} \mathrm{C}-68^{\circ} \mathrm{C}$ for $30 \mathrm{sec}$, and $72^{\circ} \mathrm{C}$ for $40 \mathrm{sec}$, and a final extension step of $72^{\circ} \mathrm{C}$ for $10 \mathrm{~min}$.

\section{Plasmid constructs}

pFlag-ABD and pMACF1-C were as in Leung et al. (1999). FlagPKNA (nucleotides 1411-2952 of mouse MACF1, GenBank accession no. AF150755) and Flag-PKNB (nucleotides 2149-3561 of mouse MACF1) were cloned in pCDNA-Flag (Leung et al. 1999). PKNC (nucleotides 2663-4016 of mouse MACF1), SR0 (nucleotides 4801-6768), SR1 (nucleotides 6769-8682), SR2 (nucleotides 8683-10644), SR3 (nucleotides 10,645-12,618), and SR4 (nucleotides 12,619-14,637) of mouse MACF1 were cloned into pKH3 (a gift of Dr. Ian Macara, University of Virginia, Charlottesville, VA). Full-length Myc-Axin, Axin deletion clones 12810, 810-956, 531-956, 531-810, and 403-600 were from Dr. Frank Costantini, (Columbia University, New York) (Fagotto et al. 1999). GST-Axin C (nucleotides 1990-2994 of rat Axin, GenBank accession no. NM 024405) was in pGEX-6P-1 (Amersham). GST-LRP6 C (nucleotides 4263-4920 of human origin, amplified from pCS-Myc-hLRP6, a gift of Dr. Christof Niehrs, Deutsches Krebsforshungszentrum, Heidelberg, Germanyl was in pGEX-6P-1 (Amersham).

\section{MACF1 siRNA vectors}

To knock down MACF1 expression in cells, nucleotides from numbers 373-393 (amino acids 68-74) of MACF1 were selected. This nucleotide sequence is not homologous to any other reported genes. The following primer pairs were designed, annealed, and cloned into the linearized vector pSuppressor according to the instructions from Gene Suppressor System
(IMGENEX). pMACF1-siRNA: 5'-CTAGAAAAAGCCGTGGT CCGAGTCGCTGATTCTCTTGAAATCAGCGACTCGGAC CACGGC- ${ }^{\prime}$ ' and ' 5'-TCGAGCCGTGGTCCGAGTCGCTGATT TCAAGAGAATCAGCGACTCGGACCACGGCTTTTT-3'. A mutated construct, pControl: 5'-TCGAGCCGTGGTCTGCGT

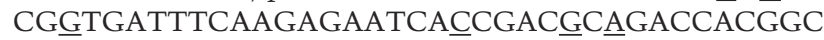
TTTTT-3' and 5'-CTAGAAAAAGCCGTGGTCTGCGTCGG TGATTCTCTTGAAATCACCGACGCAGACCACGGC-3' was used as a control. The mutated nucleotides in both palindrome sequences of pControl vector are underlined.

\section{Mammalian cell culture and cell transfection}

PC12 cells were cultured in RPMI 1640 media (Cellgro) supplemented with $10 \%$ horse serum (JRH Biosciences) and 5\% fetal bovine serum (FBS). COS-7 cells were cultured in DMEM media (Life Technologies) containing 10\% FBS. Rat-1/Wnt-1 or Rat-1 LacZ cells were cultured as described (Young et al. 1998). P19 (ATCC) cells were cultured in $\alpha$-MEM (Invitrogen) medium containing $7.5 \%$ bovine serum (Gibco), $2.5 \%$ FBS, and penicillin-streptomycin, and transfected with MACF1 siRNA vector, control vector, and pLNC-Wnt-1HA vector (a gift of Dr. Jan Kitajewski, Columbia University, New York) by the calcium phosphate method or Lipofectamine 2000 Reagent (Invitrogen). All cells were cultured in a humidified growth chamber with $5 \% \mathrm{CO}_{2}$ at $37^{\circ} \mathrm{C}$.

Whole-mount in situ immunohistochemistry, hybridization, and transferase biotin-dUTP nick end labeling (TUNEL) assay

Whole-mount in situ immunohistochemistry was performed as described by Davis (1993). The primary antibodies used include anti-MACF1 (CU119), which recognizes all isoforms of MACF1 (Lin et al. 2005), anti-T (brachyury), anti-OTX2 (Santa Cruz Biotechnology), and anti-phospho-Histone H3 (Upstate Biotechnology) antibodies. Phosphorylation of Histone H3 is correlated with chromosome condensation during cell division and used as a marker of cell proliferation. Secondary antibodies were peroxidase-conjugated anti-goat IgG or anti-rabbit IgG (Sigma). Terminal deoxynucleotidyl TUNEL staining was performed using a Cell Death Detection Kit (Roche). TUNEL assay detects DNA fragmentation that occurs during apoptosis. Images were taken with a Pixera camera attached to a dissecting microscope. Embryos were genotyped by PCR after analyses.

RNA whole-mount in situ analyses were performed as described in Correia and Conlon (2001). The probes used were Pou5f1 (Oct4; from Drs. Fatima Cavaleri and Hans Schöler, Max Planck Institute, Munster, Germany), Hesx 1 (from Dr. Sew-Lan Ang, National Institute of Medical Research, London, UK), and Lhx1 (Lim-1; from Dr. Brigid Hogan, Duke University, Durham, $\mathrm{NC)}$.

\section{Histology}

E7.5 embryos were removed intact in the uterine horns and fixed in formalin solution overnight. After dehydration in ethanol, embryos were embedded in paraffin wax, sectioned at 6- $\mu \mathrm{m}$ thickness, and stained with haematoxylin and eosin (H\&E). E9.5 embryos were dissected and then fixed in $4 \%$ paraformaldehyde overnight, then in $30 \%$ sucrose in PBS solution. The samples were embedded in OTC, sectioned at 10- $\mu \mathrm{m}$ thickness, and stained with $\mathrm{H} \& \mathrm{E}$.

\section{Immunoprecipitation and Western blotting}

Cells were washed once with cold PBS, harvested, lysed in protein lysis buffer $(50 \mathrm{mM}$ Tris- $\mathrm{HCl}$ at $\mathrm{pH} 7.4,150 \mathrm{mM} \mathrm{NaCl}, 1 \%$ [v/v] Triton X-100, 5 mM EDTA, and proteinase inhibitors), and 
spun at 12,000 rpm for $15 \mathrm{~min}$ at $4^{\circ} \mathrm{C}$. The lysates were incubated with primary antibody for $1 \mathrm{~h}$ at $4^{\circ} \mathrm{C}$. Protein A agarose or protein $\mathrm{G}$ agarose (Amersham) was added and incubated at $4^{\circ} \mathrm{C}$ for $3 \mathrm{~h}$. Samples were washed three times, eluted by SDS-sample buffer, separated by SDS-PAGE, transferred to PVDF membrane, and probed with mouse monoclonal antibodies including anti-APC antibody (Abcam), anti-GSK3 $\beta$ antibody (BD Transduction), anti- $\beta$-catenin antibody (BD Transduction), anti- $\beta$-tubulin antibody (Sigma), anti-Myc antibody (9E10; Santa Cruz Biotechnology), anti-his antibody (Covance), or rabbit polyclonal antibodies including anti-Axin antibody (a gift of Dr. Roel Nusse, Stanford University, Palo Alto, CA), anti-Axin antibody (Santa Cruz Biotechnology), anti-APC antibody (Santa Cruz Biotechnology), anti-lamin A/C antibody (Santa Cruz Biotechnology), or anti-MACF1 antibody. Proteins were visualized using ECL (Amersham).

\section{Cell fractionation}

Rat1/Wnt-1 cells were transfected with MACF1 siRNA vector or control vector for $72 \mathrm{~h}$, and the nuclear and cytosolic fractions were obtained according to Chen et al. (2000). A small aliquot of each fraction was mixed with SDS-sample buffer and boiled for $5 \mathrm{~min}$ before gel fractionation and immunoblot analyses. In this preparation, the cytosolic fraction contains the membrane fraction. Total membrane fractions for coimmunoprecipitation experiments were isolated by ProteoExtract Native Membrane Protein Extraction kit (Calbiochem).

\section{TCF luciferase assay}

Rat-1/Wnt-1, Rat-1/LacZ cells, or P19 cells were seeded on a 24-well plate the day before transfection. Subsequently, the cells were incubated with $500 \mu \mathrm{L}$ of serum-free DMEM medium. The MACF1 siRNA vector or a 3-nt mutant control vector, reporter construct and transfection control construct, pGL3-OT, or pGL3-OF (both were gifts from Dr. Bert Vogelstein, Johns Hopkins University, Baltimore, MD) and Renilla luciferase (Promega) were introduced into cells using Lipofectamine 2000 Reagent (Invitrogen) or FUGENE 6 Reagent (Roche). Cells were lysed and assayed with the Dual-Luciferase Reporter Assay System (Promega) in a TD-20/20 luminometer (Turner Designs). Firefly luciferase activity was normalized by Renilla luciferase activity. Measurements were performed in triplicate. For some experiments, P19 cells were treated with Wnt-3a-conditioned medium or control medium for $15 \mathrm{~h}$ before the assay. Wnt-3a-conditioned medium and control medium were prepared as in Shibamoto et al. (1998). The activity of conditioned medium is batch by batch. For $\mathrm{LiCl}$ treatment, cells were treated with $35 \mathrm{mM} \mathrm{LiCl}$ for $15 \mathrm{~h}$ before the assay. For the TGF $\beta$ luciferase assay, cells were transfected with siRNA vectors, together with the TGF $\beta$-luciferase reporter (pSBE4-luc, a gift of Bert Vogelstein) and Renilla luciferase construct, then treated with 200 pM human TGF $\beta 1$ (BD Biosciences) for $20 \mathrm{~h}$.

\section{Quantitative real-time $R T-P C R$}

P19 cells were transfected with pLNC-Wnt-1HA and MACF1 siRNA vector or pLNC-Wnt-1HA and control vector, then total RNAs were isolated by TRIZOL Reagent (Invitrogen). Firststrand cDNA was produced by SuperScript II reverse transcriptase (Invitrogen). Quantitative analyses of the expression of $T$ (Brachyury) mRNA and control GAPDH mRNA were performed in the Smart Cycler System (Cepheid) using primer pairs of the brachyury gene: 5'-AGGCGCCTGTGTCTTTCAGC-3' and $5^{\prime}$-TTCTGGTAGGCAGTCACAGC-3'. Primer pairs of the GAPDH gene were used as a normalization control: 5 '-CTCAT GACCACAGTCCATGC-3' and 5'-GCACGTCAGATCCACG
ACGG-3'. Quantification in this system was achieved by the addition of CYBR Green I (Molecular Probes) into the PCR reaction. The fluorescent signal increases with each PCR cycle. Quantification is based on the threshold set at 30. Threshold cycles $\left(C_{t}\right)$ were transformed into relative ratio using the formula $2^{-\Delta \Delta \mathrm{C}_{\mathrm{t}}}$ (Livak and Schmittgen 2001) with normalization to GAPDH expression.

\section{Acknowledgments}

We thank the following investigators for reagents: Dr. Jan Kitajewski (Rat-1/Wnt-1, Rat-1/LacZ fibroblast cell lines, L cells, Wnt-3a-producing L cells, pLNC-Wnt-1HA expression vector), Dr. Frank Costantini (Axin clones), Dr. Christof Niehrs (LRP6 cDNA), Dr. Roel Nusse (anti-Axin antibody), and Dr. Bert Vogelstein (pGL3-OT, pGL3-OF, and pSBE4-luc plasmids). This study was supported by grants from the NIH to R.K.H.L. and the Muscular Dystrophy Association to C.M.L.

\section{References}

Arnold, S.J., Stappert, J., Bauer, A., Kispert, A., Herrmann, B.G., and Kemler, R. 2000. Brachyury is a target gene of the Wnt/ $\beta$-catenin signaling pathway. Mech. Dev. 91: 249-258.

Beddington, R.S. and Robertson, E.J. 1999. Axis development and early asymmetry in mammals. Cell 96: 195-209.

Bosher, J.M., Hahn, B.S., Legouis, R., Sookhareea, S., Weimer, R.M., Gansmuller, A., Chisholm, A.D., Rose, A.M., Bessereau, J.L., and Labouesse, M. 2003. The Caenorhabditis elegans vab-10 spectraplakin isoforms protect the epidermis against internal and external forces. J. Cell Biol. 161: 757768.

Chen, H.J., Hwong, C.L., Wang, C.H., and Hwang, J. 2000. Degradation of DNA topoisomerase I by a novel trypsin-like serine protease in proliferating human $\mathrm{T}$ lymphocytes. J. Biol. Chem. 275: 13109-13117.

Cliffe, A., Hamada, F., and Bienz, M. 2003. A role of Dishevelled in relocating Axin to the plasma membrane during wingless signaling. Curr. Biol. 13: 960-966.

Correia, K.M. and Conlon, R.A. 2001. Whole-mount in situ hybridization to mouse embryos. Methods 23: 335-338.

Cunliffe, V. and Smith, J.C. 1992. Ectopic mesoderm formation in Xenopus embryos caused by widespread expression of a Brachyury homologue. Nature 358: 427-430.

Davis, C.A. 1993. Whole-mount immunohistochemistry. Methods Enzymol. 225: 502-516.

Dufort, D., Schwartz, L., Harpal, K., and Rossant, J. 1998. The transcription factor HNF3 $\beta$ is required in visceral endoderm for normal primitive streak morphogenesis. Development 125: 3015-3025.

Fagotto, F., Jho, E., Zeng, L., Kurth, T., Joos, T., Kaufmann, C., and Costantini, F. 1999. Domains of axin involved in protein-protein interactions, Wnt pathway inhibition, and intracellular localization. J. Cell Biol. 145: 741-756.

Karakesisoglou, I., Yang, Y., and Fuchs, E. 2000. An epidermal plakin that integrates actin and microtubule networks at cellular junctions. J. Cell Biol. 149: 195-208.

Kelly, O.G., Pinson, K.I., and Skarnes, W.C. 2004. The Wnt co-receptors Lrp5 and Lrp6 are essential for gastrulation in mice. Development 131: 2803-2815.

Kikuchi, A. 2000. Regulation of $\beta$-catenin signaling in the Wnt pathway. Biochem. Biophys. Res. Commun. 268: 243-248.

Kishida, M., Koyama, S., Kishida, S., Matsubara, K., Nakashima, S., Higano, K., Takada, R., Takada, S., and Kikuchi, A. 1999. 
Axin prevents Wnt-3a-induced accumulation of $\beta$-catenin. Oncogene 18: 979-985.

Kodama, A., Karakesisoglou, I., Wong, E., Vaezi, A., and Fuchs, E. 2003. ACF7: An essential integrator of microtubule dynamics. Cell 115: 343-354.

Lako, M., Lindsay, S., Lincoln, J., Cairns, P.M., Armstrong, L., and Hole, N. 2001. Characterisation of Wnt gene expression during the differentiation of murine embryonic stem cells in vitro: Role of Wnt3 in enhancing haematopoietic differentiation. Mech. Dev. 103: 49-59.

Lee, E., Salic, A., Kruger, R., Heinrich, R., and Kirschner, M.W. 2003. The roles of APC and Axin derived from experimental and theoretical analysis of the Wnt pathway. PLOS Biol. 1: E10.

Leung, C.L., Sun, D., Zheng, M., Knowles, D.R., and Liem, R.K. 1999. Microtubule actin cross-linking factor (MACF): A hybrid of dystonin and dystrophin that can interact with the actin and microtubule cytoskeletons. J. Cell Biol. 147: 12751286.

Leung, C.L., Green, K.J., and Liem, R.K. 2002. Plakins: A family of versatile cytolinker proteins. Trends Cell Biol. 12: 37-45.

Lin, C.M., Chen, H.J., Leung, C.L., Parry, D.A., and Liem, R.K. 2005. Microtubule actin crosslinking factor $1 \mathrm{~b}$ : A novel plakin that localizes to the Golgi complex. J. Cell Sci. 118: 3727-3738.

Liu, P., Wakamiya, M., Shea, M.J., Albrecht, U., Behringer, R.R., and Bradley, A. 1999. Requirement for Wnt3 in vertebrate axis formation. Nat. Genet. 22: 361-365.

Livak, K.J. and Schmittgen, T.D. 2001. Analysis of relative gene expression data using real-time quantitative PCR and the $22^{-\Delta \Delta \mathrm{CT}_{\mathrm{T}}}$ method. Methods 25: 402-408.

Mao, J., Wang, J., Liu, B., Pan, W., Farr III, G.H., Flynn, C., Yuan, H., Takada, S., Kimelman, D., Li, L., et al. 2001. Low-density lipoprotein receptor-related protein-5 binds to Axin and regulates the canonical Wnt signaling pathway. Mol. Cell 7: 801-809.

Nusse, R. 2005. Wnt signaling in disease and in development. Cell Res. 15: 28-32.

O'Reilly, M.A., Smith, J.C., and Cunliffe, V. 1995. Patterning of the mesoderm in Xenopus: Dose-dependent and synergistic effects of Brachyury and Pintallavis. Development 121: 1351-1359.

Packard, M., Mathew, D., and Budnik, V. 2003. Wnts and TGF $\beta$ in synaptogenesis: Old friends signalling at new places. Nat. Rev. Neurosci. 4: 113-120.

Roper, K. and Brown, N.H. 2003. Maintaining epithelial integrity: A function for gigantic spectraplakin isoforms in adherens junctions. J. Cell Biol. 162: 1305-1315.

Rosner, M.H., Vigano, M.A., Ozato, K., Timmons, P.M., Poirier, F., Rigby, P.W., and Staudt, L.M. 1990. A POU-domain transcription factor in early stem cells and germ cells of the mammalian embryo. Nature 345: 686-692.

Shibamoto, S., Higano, K., Takada, R., Ito, F., Takeichi, M., and Takada, S. 1998. Cytoskeletal reorganization by soluble Wnt-3a protein signalling. Genes Cells 3: 659-670.

Simeone, A., Acampora, D., Mallamaci, A., Stornaiuolo, A., D'Apice, M.R., Nigro, V., and Boncinelli, E. 1993. A vertebrate gene related to orthodenticle contains a homeodomain of the bicoid class and demarcates anterior neuroectoderm in the gastrulating mouse embryo. EMBO J. 12: 2735-2747.

Strutt, D. 2003. Frizzled signalling and cell polarisation in Drosophila and vertebrates. Development 130: 4501-4513.

Sun, D., Leung, C.L., and Liem, R.K. 2001. Characterization of the microtubule binding domain of microtubule actin crosslinking factor (MACF): Identification of a novel group of microtubule associated proteins. J. Cell Sci. 114: 161-172.
Tolwinski, N.S., Wehrli, M., Rives, A., Erdeniz, N., DiNardo, S., and Wieschaus, E. 2003. Wg/Wnt signal can be transmitted through arrow/LRP5,6 and Axin independently of Zw3/ Gsk3 $\beta$ activity. Dev. Cell 4: 407-418.

Veeman, M.T., Axelrod, J.D., and Moon, R.T. 2003. A second canon. Functions and mechanisms of $\beta$-catenin-independent Wnt signaling. Dev. Cell 5: 367-377.

Willert, K., Shibamoto, S., and Nusse, R. 1999. Wnt-induced dephosphorylation of Axin releases $\beta$-catenin from the Axin complex. Genes \& Dev. 13: 1768-1773.

Willison, K. 1990. The mouse Brachyury gene and mesoderm formation. Trends Genet. 6: 104-105.

Yamaguchi, H., Niimi, T., Kitagawa, Y., and Miki, K. 1999a. Brachyury $(\mathrm{T})$ expression in embryonal carcinoma P19 cells resembles its expression in primitive streak and tail-bud but not that in notochord. Dev. Growth Differ. 41: 253-264.

Yamaguchi, T.P., Takada, S., Yoshikawa, Y., Wu, N., and McMahon, A.P. 1999b. T (Brachyury) is a direct target of Wnt3a during paraxial mesoderm specification. Genes \& Dev. 13: $3185-3190$

Yamamoto, H., Kishida, S., Kishida, M., Ikeda, S., Takada, S., and Kikuchi, A. 1999. Phosphorylation of axin, a Wnt signal negative regulator, by glycogen synthase kinase- $3 \beta$ regulates its stability. J. Biol. Chem. 274: 10681-10684.

Young, C.S., Kitamura, M., Hardy, S., and Kitajewski, J. 1998. Wnt- 1 induces growth, cytosolic $\beta$-catenin, and Tcf/Lef transcriptional activation in Rat-1 fibroblasts. Mol. Cell. Biol. 18: $2474-2485$. 


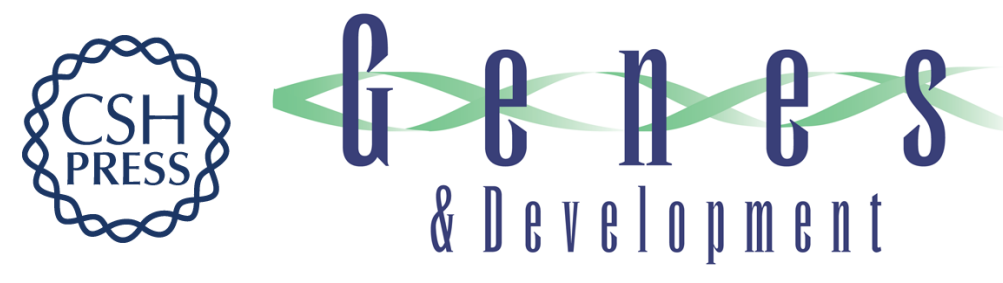

\section{The role of microtubule actin cross-linking factor 1 (MACF1) in the Wnt signaling pathway}

Hui-Jye Chen, Chung-Ming Lin, Chyuan-Sheng Lin, et al.

Genes Dev. 2006, 20:

Access the most recent version at doi:10.1101/gad.1411206

\section{Supplemental http://genesdev.cshlp.org/content/suppl/2006/06/30/gad.1411206.DC1 Material}

References This article cites 40 articles, 16 of which can be accessed free at: http://genesdev.cshlp.org/content/20/14/1933.full.html\#ref-list-1

\section{License}

Email Alerting

Receive free email alerts when new articles cite this article - sign up in the box at the top Service 